\title{
Melanoma of the Conjunctiva Pathologic TNM Finding v7
}

National Cancer Institute

\section{Source}

National Cancer Institute. Melanoma of the Conjunctiva Pathologic TNM Finding v7. NCI

Thesaurus. Code C88614.

A pathologic finding about one or more characteristics of melanoma of the conjunctiva, following the rules of the TNM AJCC V7 classification system. Complete resection of the primary site is indicated. Histopathologic evaluation for negative peripheral and deep margins should be performed. To best judge the depth of penetration of the tumor, sections should be made perpendicular to the epithelial surface. (from AJCC 7th Ed.) 